\title{
The role of induced pluripotent stem cells in regenerative medicine: neurodegenerative diseases
}

\author{
Jun Peng and Xianmin Zeng*
}

\begin{abstract}
Alzheimer's disease, Parkinson's disease, Huntington's disease, amyotrophic lateral sclerosis, and Friedreich's ataxia are the most common human neurodegenerative diseases pathologically characterized by a progressive and specific loss of certain neuronal populations. The exact mechanisms of neuronal cell death in these diseases are unclear, although some forms of the diseases are inherited and genes causing these diseases have been identified. Currently there are no effective clinical therapies for many of these diseases. The recently acquired ability to reprogram human adult somatic cells to induced pluripotent stem cells (iPSCs) in culture may provide a powerful tool for in vitro neurodegenerative disease modeling and an unlimited source for cell replacement therapy. In the present review, we summarize recent progress on iPSC generation and differentiation into neuronal cell types and discuss the potential application for in vitro disease mechanism study and in vivo cell replacement therapy.
\end{abstract}

\section{Introduction}

Neurodegenerative diseases describe a clinical condition characterized by the selective and progressive loss of neurons, eventually leading to cognitive, behavioral, and physical defects that can cause the death of the patient. Some of these diseases, including Alzheimer's disease (AD), Parkinson's disease (PD), and amyotrophic lateral sclerosis (ALS), are sporadic and, in some instances, are inherited with gene mutations. Huntington's disease (HD) and Friedreich's ataxia (FRDA) are acquired in an entirely genetic manner. The exact mechanisms of the

*Correspondence: xzeng@buckinstitute.org

Buck Institute for Research on Aging, 8001 Redwood Boulevard, Novato, CA 94945 , USA neuronal cell death are still unclear, although mutant genes causing these diseases have been identified. For the most part, there are no effective therapies.

The study of the underlying molecular mechanisms of these diseases and the development of new treatments for these devastating human neurodegenerative disorders have been hindered by the lack of appropriate model systems. Differentiated neurons derived from patientspecific induced pluripotent stem cells (iPSCs), however, are proving to be useful in investigations of the causes of neurodegenerative diseases and the search for drug targets that interrupt the disease processes. Transplantation of differentiated neurons offers a promising therapeutic strategy for minimizing the functional damage involved in neurodegenerative disorders.

\section{Induced pluripotent stem cells}

Following the seminal report on the ability to reprogram mouse fibroblast cells to a pluripotent state using four transcription factors (Oct4, Sox2, Klf4, and c-Myc) by Takahashi and Yamanaka in 2006 [1], cells from different somatic lineages and other species including human [2-5], pig [6], rat [7], rhesus monkey [8], marmoset [9], and sheep [10] have been reprogrammed successfully to iPSCs. Several other transcription factors (not just these four factors) have also been used to induce pluripotency successfully [11]. Depending on the cell type, it has been shown that fewer transcription factors may be sufficient for reprogramming, perhaps as few as one factor in neural stem cells [12]. It appears that the method of factor delivery is not critical as iPSC lines have been generated using retroviruses, lentiviruses, adenoviruses, and protein delivery of factors. Methods of transient delivery of factors allow us to define the window of time when changes occur and the sequence of application that will allow for the largest numbers of cells to be reprogrammed.

One important observation is that the reprogramming factors are not needed forever. Indeed, once the cells are reprogrammed, they express endogenous pluripotency genes and silence the exogenous ones - and thus, like 
embryonic stem cells or other pluripotent cells, iPSCs can readily differentiate into appropriate lineages. This observation has been utilized cleverly by several groups to develop zero footprinting technology that allows one to reprogram somatic cells with factors or genes that can then be permanently eliminated, leaving cells that at least theoretically should be indistinguishable from embryonic stem cells derived in a conventional fashion. Such techniques include the use of Cre/Lox [3,13], piggyBac [14], and sleeping beauty transposons to efficiently eliminate integrating particles, and the more recent techniques of using plasmids [15] and other episomal strategies that are effectively diluted out as the cells divide [16], as well as using RNA [17], proteins [18], and small molecules that reduce the probability of any potential unintended integrating event to zero [19].

In parallel to reprogramming, testing the ability of iPSCs to behave like embryonic stem cells has been initiated. These experiments include making chimeras in mice, demonstrating germline transmission and following F1 and F2 generations over a couple of years, using genome-wide gene expression analysis, epigenetic profiling, and miRNA expression as well as functional testing in animal models of disease. Although there are few direct side by side comparisons that might reveal subtle differences, the results to a large extent confirm that the cells behave virtually identically to each other irrespective of the path to pluripotency [20]. Nevertheless some differences have been observed. For example, the observed frequency of karyotypic abnormalities seems to be higher in iPSCs, which is not unexpected giving the additional culture and genomic alterations that are known to occur with viral transduction and selection pressures. Anecdotal evidence suggests that teratomas from iPSCs appear less complex and more cystic, the frequency and extent of chimerism is smaller, and there appear biases depending on the cell of origin of the pluripotent population. Whether these differences are significant and wider than normal allelic differences, however, remains to be seen [20].

Human iPSCs represent a promising cell source for generating patient-specific and/or disease-specific pluripotent cells and subsequently generating differentiated cell types that are impaired by diseases. This approach is particularly promising for studying neurodegenerative diseases in vitro where primary human neurons are not available for experiments. In the present manuscript we will discuss potential applications of human iPSCs in neurodegenerative diseases and recent advances in such potentials.

\section{Neurodegenerative diseases}

$\mathrm{AD}$ is associated with the selective damage of brain regions and neural circuits critical for cognition and memory, including neurons in the neocortex, hippocampus, amygdala, basal forebrain cholinergic system, and brainstem monoaminergic nuclei. Pathological features of $\mathrm{AD}$ are characterized by histological lesions including extracellular senile plaques and intracellular neurofibrillary tangles, which contain fibrillar $\beta$-amyloid $(\mathrm{A} \beta)$ and hyperphosphorylated tau proteins, respectively [21]. Most cases of AD are sporadic, but autosomaldominant, familial $\mathrm{AD}$ is also seen with mutations in presenilin and amyloid precursor protein. In addition, genetic variations in the genes coding for apolipoprotein $\mathrm{E}$ and ubiquitin 1 also appear to modify the disease risk [22]. Although the mechanisms of how such genetic mutations lead to the disease remains elusive, toxic effects of cleavage products of amyloid precursor protein have received the most attention. One dominant hypothesis concerning the etiology and pathogenesis of $\mathrm{AD}$ is the so-called amyloid cascade hypothesis [22]. This theory currently suggests that the production of longer $\mathrm{A} \beta$ peptides, particularly in a highly toxic oligomeric form, results in aggregation and deposition of $A \beta$ in the brain. Aggregated $A \beta$ leads to neuronal toxicity, resulting in neurofibrillary degeneration, microglial activation, and, ultimately, synaptic and neuronal loss.

PD is a common age-related neurodegenerative disorder that is pathologically characterized by the selective loss of nigrostriatal dopaminergic neurons in the substantia nigra pars compacta region of the ventral midbrain and by the presence of ubiquinated protein deposits in residual neurons (Lewy bodies) [23-25]. Genes identified to date that cause familial forms of the disease include $\alpha$-synuclein, ubiquitin carboxy-terminal hydrolase L1, parkin, DJ-1, putative serine threonine kinase 1, and leucine-rich repeat kinase 2. Although the molecular connection between these various familial parkinsonisms is currently difficult to make, human PD as a consequence of genetic mutations in these genes appears to have a common endpoint of nigrostriatal dopaminergic neuronal degeneration [23-25]. Epidemiological evidence has suggested that environmental agents in combination with genetic susceptibility may also be responsible for the associated neurodegeneration in PD [26-29].

HD, a dominant inherited neurodegenerative disorder, is caused by abnormal expansion of the CAG repeat (36 repeats or more) in exon 1 of the huntingtin (htt) gene located on chromosome 4p16.3. HD patients exhibit neuronal degeneration predominantly in the striatum and the cerebral cortex. Medium spiny neurons that contain $\gamma$-aminobutyric acid and enkephalin are most susceptible to dysfunction and degeneration early in the striatum of the disease. Cortical pyramidal neurons degenerate before the onset of clinical features of HD. With disease progression, neuronal loss becomes more global, affecting numerous brain areas [30-32]. Multiple 
molecular pathways are involved in the pathogenesis of $\mathrm{HD}$, including abnormal protein aggregation and proteolysis, excitotoxicity, transcriptional dysregulation, mitochondrial dysfunction, and changes in axonal transport and synaptic dysfunction [30-32].

ALS, also referred to as Lou Gehrig's disease, is a rapidly progressive, invariably fatal neurodegenerative disorder that affects motor neurons in the motor cortex, brainstem, and spinal cord. The majority of the disease cases are sporadic, yet mutations have been identified in familial cases of ALS [33]. Approximately $20 \%$ of familial ALS cases are caused by autosomal dominant mutations in superoxide dismutase 1 (SOD1), a ubiquitously expressed cytoplasmic enzyme [34]. More than 140 different SOD1 mutations have been identified that all cause a rather similar disease phenotype. All mutants show reduced conformational stability and cause the accumulation of hydrophobic and aggregation-prone SOD1 subfractions when expressed in cellular and transgenic mouse models [33,35]. Several mechanisms have been proposed to explain motor neuron death in ALS, including glutamate-induced excitotoxicity, cytoskeletal abnormalities, protein aggregation, oxidative stress, angiogenic factors, mitochondrial dysfunction, and extracellular SOD1 toxicity [33,35].

FRDA, the most common autosomal recessive ataxia, affects both central and peripheral nervous systems: heart, skeleton, and endocrine pancreas. The disease is caused by expansion of a guanine-adenine-adenine trinucleotide repeat located within the first intron of the frataxin gene on chromosome 9q13 [36]. Frataxin is found primarily in mitochondria. Deficiency of frataxin results in mitochondrial iron accumulation, defects in specific mitochondrial enzymes, enhanced sensitivity to oxidative stress, and, eventually, free-radical mediated cell death [37].

\section{iPSC potential applications in neurodegenerative diseases}

One strategy to study neurodegenerative diseases is to generate experimental models that mimic the initiation and progression of the disease. Human neurons present great challenges for the development of an adequate model system that closely resembles the process of neuron degeneration in neurodegenerative diseases, because normal neurons do not generally divide and are thus not readily maintained in vitro. Currently available model systems such as animal models, immortalized cell lines, and primary cultures have limitations and have not contributed further to an understanding of both the important pathology and potential neuroprotective therapeutics for neurodegenerative diseases. The recent acquired ability to reprogram adult somatic cells to iPSCs and advances in differentiating iPSCs to specific somatic cell types, however, have the potential to overcome the inherent limitations of existing disease model systems [38]. In theory, disease-specific and patient-specific iPSCs can be directed to differentiate into any specific neuronal cell types that maintain the disease genotype and phenotype, which potentially can provide more relevant human disease models. Disease-specific iPSCs thus represent a promising resource that explores disease mechanisms, discovers candidate drugs, and develops new therapies.

Such in vitro disease modeling by iPSCs will define some of the in vivo events occurring in these disorders and will allow for direct examination of the unique features of human neurons with respect to their responses to environmental and chemical toxins as well as pharmacological agents. Consequently, such studies will provide important information concerning potential molecular targets and approaches for therapy that can be tested in the laboratory. The demonstration of therapeutic efficacies in these neurodegenerative disease model systems should then be directly transformed into new treatments for these devastating illnesses [38].

Indeed, efforts on iPSC-based neurodegenerative disease modeling and potential cell replacement therapy have been initiated by several research groups. One of the first studies reported the reprogramming of iPSCs from an ALS patient. Dimos and colleagues have shown that fibroblasts from an elderly patient diagnosed with ALS-associated mutations in the gene encoding SOD1 could be efficiently reprogrammed to iPSCs. They also demonstrated that these patient-derived iPSCs could be subsequently differentiated into motor neurons and glia. Importantly, analysis of quantitative reverse transcription PCR reveal that these patient-specific iPSCs possess a gene expression signature similar to that of human embryonic stem cells (hESCs) and can be differentiated into cell types representative of each of the three embryonic germ layers [4]. In addition, Park and colleagues obtained fibroblasts from a young patient with HDassociated mutations in the gene encoding huntingtin $(h t t)$. Fibroblasts from a skin biopsy of this patient were transduced with retroviruses that expressed the four key transcription factors (Oct4, Sox2, Klf4, and c-Myc), thus producing induced iPSCs. These patient-specific iPSCs possess properties of hESCs when grown in co-culture with mouse embryonic feeder fibroblasts [5]. One anticipates that this approach will be immediately useful in the analysis of neurodegenerative diseases. Understanding how mutant genes such as SOD1 and $h t t$ alter cellular response to perturbations is crucial, especially for investigating disease mechanisms and developing selective therapeutics.

More recently, $\mathrm{Ku}$ and colleagues reported the generation of iPSC lines derived from FRDA patient fibroblasts 
[39]. The authors found that the long GAA - TTC repeats in the mutant FXN alleles undergo further expansion during the reprogramming of FRDA fibroblasts and that the repeat instability observed in the iPSCs is highly similar to FRDA patient families. Ku and colleagues also observed that the mismatch repair enzyme $\mathrm{MSH} 2$ is significantly increased in FRDA iPSCs and that lentiviral shRNA silencing of the $M S H 2$ gene in iPSCs decreases the scale of repeat expansions of the mutant FRDA alleles, providing valuable models to study the cellular pathology of FRDA and to develop high-throughput drug screening assays.

Since neuronal degeneration in PD is relatively focal and since dopaminergic neurons can be efficiently generated from hESCs [40], PD might provide an ideal disease for iPSC-based diseasing modeling and cell therapy. iPSC lines reprogrammed from fibroblasts of patients with idiopathic PD were first reported by Soldner and colleagues using the four Yamanaka factors, which were then excised by Cre-mediated recombination in 2009 [3]. The authors showed these viral vector-free iPSCs could differentiate into tyrosine hydroxylase-positive cells. We recently reported the efficient generation of dopaminergic neurons from multiple human iPSC lines that functioned in vivo in a PD animal model for the first time [2]. Using a scalable process for the production of functional dopaminergic neurons we have developed for hESCs in xeno-free defined conditions that are suitable for potential clinical use, we showed that neural stem cells derived from two human iPSC lines adapted to defined media were able to differentiate into functional dopaminergic neurons similar to hESCs in terms of time course, neural patterning, and efficiency of generation of dopaminergic neurons. Side by side comparison of iPSCs and hESCs as well as of iPSC-derived and hESC-derived neural stem cells and dopaminergic neurons revealed that iPSCs were overall similar to hESCs in gene expression profiles. Importantly, iPSC-derived dopaminergic neurons were functional as they survived and improved behavioral deficits in 6-hydroxydopaminelesioned rats after transplantation. This approach will not only facilitate subsequent adaptation of protocols to Good Manufacturing Practice standards, which is a prerequisite for progression towards clinical trials, but also offer an unprecedented opportunity to generate a large number of dopaminergic neurons for in vitro studies of the mechanisms of disease. More recently, transplantation to 6-hydroxydopamine-lesioned parkinsonian rats by Hargus and colleagues showed that a dopaminergic population derived from PD iPSCs could survive and restore both amphetamine-induced functions, and that the grafts contained large numbers of midbrain dopamine neurons, which innervated the host striatum [41].
The basal forebrain cholinergic neurons provide a widespread excitatory projection to the cerebral cortex and hippocampus. These neurons are involved in various higher cortical functions such as the maintenance of attention and wakefulness and the processing of shortterm and long-term memory [42]. Key neuropathological findings in individuals with AD include a selective loss of cholinergic neurons of the basal forebrain and the presence of extracellular and intracellular plaques composed of $\mathrm{A} \beta$ protein. Their degeneration has been linked to memory and cognitive impairment seen in $\mathrm{AD}$ [22]. More recently, Bissonnette and colleagues demonstrated that transcription factors important for in vivo forebrain development can be systematically applied to direct hESC differentiation into functional basal forebrain cholinergic neurons in vitro [43]. This experimental system also provides a powerful tool to create functional basal forebrain cholinergic neurons using iPSCs from AD patients.

\section{Conclusions}

Although iPSC research is still in its infancy (less than 5 years have been passed since the first generation of iPSCs in 2006), the field has moved rapidly and exciting progress has been made. The ability to generate diseasespecific iPSC lines from patients and to differentiate them into neuronal cells has allowed investigators to produce neurons that recapitulate some, if not all, of the features of neurodegenerative diseases that are otherwise unavailable. These model systems are predicated to be very useful in explorations of the nature of biochemical alterations in neural cells, the evolution of pathologies, and the pathogenic mechanisms. Furthermore, the development of models for these disorders is accelerating efforts to translate insights related to neurodegenerative mechanisms into disease-modifying therapies. Importantly, the iPSC system described here will also robustly model environmental risk factor-induced neurodegenerative diseases and will be used to ask questions about the environmental risk factors that interact with gene products and pathways and contribute to disease development.

Ongoing studies are exploring the iPSC-based potential application in other neurological diseases. For example, Rett syndrome is a neurodevelopmental autism spectrum disorder that affects girls due primarily to mutations in the X-linked gene encoding methyl-CpG binding protein 2. Using iPSCs from female Rett syndrome patients' fibroblasts, Marchetto and colleagues have created functional neurons that provide the first human cellular model for studying Rett syndrome and could be amenable to cell therapy and drug screens [44].

iPSC-based therapy for neurodegenerative diseases is an extremely exciting new therapeutic approach that is in 
the early stages of development. There are numerous challenges that remain before iPSC clinical applications. Several neurodegenerative conditions are noncell autonomous and neuronal death is driven by factors in the cellular microenvironment, such as inflammation. This is critical for iPSC replacement therapies because implantation of iPSC-derived neurons into a "bad neighborhood' will result in their inevitable death. The implantation of non-neuronal cells (astrocytes, oligodendrocytes) to refine the microenvironment is thus a viable strategy. In addition, lentiviral and retroviral vectors were recently used in delivery of reprogramming factors to generate iPSCs. Theses vectors may integrate into the genome in the host cells. The integration site is also unpredictable, which can disturb the function of cellular genes and lead to activation of oncogenes, thereby promoting tumorigenesis. Furthermore, the reprogramming process and subsequent culture can induce copy number variations [45], point mutations [46], and abnormal DNA methylation patterns [47] during generation of iPSCs, which may affect their clinical use.

This article is part of a review series on Induced pluripotent stem cells. Other articles in the series can be found online at http://stemcellres.com/series/ipsc

\section{Abbreviations}

$A \beta$, amyloid $\beta ; A D$, Alzheimer's disease; ALS, amyotrophic lateral sclerosis; FRDA, Friedreich's ataxia; HD, Huntington's disease; hESC, human embryonic stem cell; iPSC, induced pluripotent stem cell; miRNA, microRNA; PCR, polymerase chain reaction; PD, Parkinson's disease; shRNA, short hairpin RNA; SOD1, superoxide dismutase 1.

\section{Competing interests}

The authors declare that they have no competing interests.

Published: 28 July 2011

\section{References}

1. Takahashi K, Yamanaka S: Induction of pluripotent stem cells from mouse embryonic and adult fibroblast cultures by defined factors. Cell 2006, 126:663-676.

2. Swistowski A, Peng J, Liu Q, Mali P, Rao MS, Cheng L, Zeng X: Efficient generation of functional dopaminergic neurons from human induced pluripotent stem cells under defined conditions. Stem Cells 2010, 28:1893-1904.

3. Soldner F, Hockemeyer D, Beard C, Gao Q, Bell GW, Cook EG, Hargus G, Blak A, Cooper O, Mitalipova M, Isacson O, Jaenisch R: Parkinson's disease patientderived induced pluripotent stem cells free of viral reprogramming factors. Cell 2009, 136:964-977.

4. Dimos JT, Rodolfa KT, Niakan KK, Weisenthal LM, Mitsumoto H, Chung W, Croft GF, Saphier G, Leibel R, Goland R, Wichterle H, Henderson CE, Eggan K: Induced pluripotent stem cells generated from patients with ALS can be differentiated into motor neurons. Science 2008, 321:1218-1221.

5. Park IH, Arora N, Huo H, Maherali N, Ahfeldt T, Shimamura A, Lensch MW, Cowan C, Hochedlinger K, Daley GQ: Disease-specific induced pluripotent stem cells. Cell 2008, 134:877-886.

6. Esteban MA, Xu J, Yang J, Peng M, Qin D, Li W, Jiang Z, Chen J, Deng K, Zhong M, Cai J, Lai L, Pei D: Generation of induced pluripotent stem cell lines from Tibetan miniature pig. J Bio/ Chem 2009, 284:17634-17640.

7. Chang MY, Kim D, Kim CH, Kang HC, Yang E, Moon Jl, Ko S, Park J, Park KS, Lee KA, Hwang DY, Chung Y, Lanza R, Kim KS: Direct reprogramming of rat neural precursor cells and fibroblasts into pluripotent stem cells. PLoS One
2010, 5:e9838

8. Liu H, Zhu F, Yong J, Zhang P, Hou P, Li H, Jiang W, Cai J, Liu M, Cui K, Qu X, Xiang T, Lu D, Chi X, Gao G, Ji W, Ding M, Deng H: Generation of induced pluripotent stem cells from adult rhesus monkey fibroblasts. Cell Stem Cell 2008, 3:587-590.

9. Wu Y, Zhang Y, Mishra A, Tardif SD, Hornsby PJ: Generation of induced pluripotent stem cells from newborn marmoset skin fibroblasts. Stem Cell Res 2010, 4:180-188.

10. Li Y, Cang M, Lee AS, Zhang K, Liu D: Reprogramming of sheep fibroblasts into pluripotency under a drug-inducible expression of mouse-derived defined factors. PLoS One 2011, 6:e15947.

11. Yu J, Vodyanik MA, Smuga-Otto K, Antosiewicz-Bourget J, Frane JL, Tian S, Nie J, Jonsdottir GA, Ruotti V, Stewart R, Slukvin, II, Thomson JA: Induced pluripotent stem cell lines derived from human somatic cells. Science 2007, 318:1917-1920.

12. Kim JB, Greber B, Arauzo-Bravo MJ, Meyer J, Park KI, Zaehres H, Scholer HR: Direct reprogramming of human neural stem cells by OCT4. Nature 2009, 461:649-653.

13. Kaji K, Norrby K, Paca A, Mileikovsky M, Mohseni P, Woltjen K: Virus-free induction of pluripotency and subsequent excision of reprogramming factors. Nature 2009, 458:771-775.

14. Woltjen K, Michael IP, Mohseni P, Desai R, Mileikovsky M, Hamalainen R, Cowling R, Wang W, Liu P, Gertsenstein M, Kaji K, Sung HK, Nagy A: piggyBac transposition reprograms fibroblasts to induced pluripotent stem cells. Nature 2009, 458:766-770

15. Okita K, Nakagawa M, Hyenjong H, Ichisaka T, Yamanaka S: Generation of mouse induced pluripotent stem cells without viral vectors. Science 2008, 322:949-953.

16. Yu J, Hu K, Smuga-Otto K, Tian S, Stewart R, Slukvin, II, Thomson JA: Human induced pluripotent stem cells free of vector and transgene sequences. Science 2009, 324:797-801.

17. Warren L, Manos PD, Ahfeldt T, Loh YH, Li H, Lau F, Ebina W, Mandal PK, Smith ZD, Meissner A, Daley GQ, Brack AS, Collins JJ, Cowan C, Schlaeger TM, Rossi DJ: Highly efficient reprogramming to pluripotency and directed differentiation of human cells with synthetic modified mRNA. Cell Stem Cell 2010, 7:618-630

18. Zhou H, Wu S, Joo JY, Zhu S, Han DW, Lin T, Trauger S, Bien G, Yao S, Zhu Y, Siuzdak G, Scholer HR, Duan L, Ding S: Generation of induced pluripotent stem cells using recombinant proteins. Cell Stem Cell 2009, 4:381-384.

19. Lyssiotis CA, Foreman RK, Staerk J, Garcia M, Mathur D, Markoulaki S, Hanna J, Lairson LL, Charette BD, Bouchez LC, Bollong M, Kunick C, Brinker A, Cho CY, Schultz PG, Jaenisch R: Reprogramming of murine fibroblasts to induced pluripotent stem cells with chemical complementation of Klf4. Proc Natl Acad Sci U S A 2009, 106:8912-8917.

20. Yamanaka S, Blau HM: Nuclear reprogramming to a pluripotent state by three approaches. Nature 2010, 465:704-712.

21. Selkoe DJ: Alzheimer's disease results from the cerebral accumulation and cytotoxicity of amyloid beta-protein. J Alzheimers Dis 2001, 3:75-80.

22. Bertram L, Tanzi RE: Thirty years of Alzheimer's disease genetics: the implications of systematic meta-analyses. Nat Rev Neurosci 2008, 9:768-778.

23. Dauer W, Przedborski S: Parkinson's disease: mechanisms and models. Neuron 2003, 39:889-909.

24. Forno LS: Neuropathology of Parkinson's disease. J Neuropathol Exp Neurol 1996, 55:259-272.

25. Lang AE, Lozano AM: Parkinson's disease. First of two parts. N Engl J Med 1998, 339:1044-1053.

26. Tanner CM, Ottman R, Goldman SM, Ellenberg J, Chan P, Mayeux R, Langston JW: Parkinson disease in twins: an etiologic study. JAMA 1999, 281:341-346.

27. Gorell JM, Johnson CC, Rybicki BA, Peterson EL, Richardson RJ: The risk of Parkinson's disease with exposure to pesticides, farming, well water, and rural living. Neurology 1998, 50:1346-1350.

28. Jimenez-Jimenez FJ, Mateo D, Gimenez-Roldan S: Exposure to well water and pesticides in Parkinson's disease: a case-control study in the Madrid area. Mov Disord 1992, 7:149-152.

29. Stephenson J: Exposure to home pesticides linked to Parkinson disease. JAMA 2000, 283:3055-3056.

30. Young AB: Huntingtin in health and disease. J Clin Invest 2003, 111:299-302

31. Roze E, Bonnet C, Betuing S, Caboche J: Huntington's disease. Adv Exp Med Biol 2010, 685:45-63.

32. Ross CA, Tabrizi SJ: Huntington's disease: from molecular pathogenesis to clinical treatment. Lancet Neurol 2011, 10:83-98. 
33. Pasinelli P, Brown RH: Molecular biology of amyotrophic lateral sclerosis: insights from genetics. Nat Rev Neurosci 2006, 7:710-723.

34. Rosen DR, Siddique T, Patterson D, Figlewicz DA, Sapp P, Hentati A, Donaldson D, Goto J, O'Regan JP, Deng H-X, Rahmani Z, Krizus A, McKenna-Yasek D, Cayabyab A, Gaston SM, Berger R, Tanzi RE, Halperin J, Herzfeldt B, Van den Vergh R, Hung W-Y, Bird T, Deng G, Mulder DW, Smyth C, Laing NG, Soriano E, Pericak-Vance MA, Haines J, Rouleau GA, et al:: Mutations in Cu/Zn superoxide dismutase gene are associated with familial amyotrophic lateral sclerosis. Nature 1993, 362:59-62.

35. Shaw BF, Valentine JS: How do ALS-associated mutations in superoxide dismutase 1 promote aggregation of the protein? Trends Biochem Sci 2007, 32:78-85.

36. Campuzano V, Montermini L, Molto MD, Pianese L, Cossee M, Cavalcanti F, Monros E, Rodius F, Duclos F, Monticelli A, Zara F, Canizares J, Koutnikova H, Bidichandani SI, Gellera C, Brice A, Trouillas P, De Michele G, Filla A, De Frutos R, Palau F, Patel PI, Di Donato S, Mandel JL, Cocozza S, Koenig M, Pandolfo M: Friedreich's ataxia: autosomal recessive disease caused by an intronic GAA triplet repeat expansion. Science 1996, 271:1423-1427.

37. Stemmler TL, Lesuisse E, Pain D, Dancis A: Frataxin and mitochondrial FeS cluster biogenesis. J Biol Chem 2010, 285:26737-26743.

38. Jopling C, Boue S, Izpisua Belmonte JC: Dedifferentiation, transdifferentiation and reprogramming: three routes to regeneration. Nat Rev Mol Cell Biol 2011, 12:79-89.

39. Ku S, Soragni E, Campau E, Thomas EA, Altun G, Laurent LC, Loring JF, Napierala M, Gottesfeld JM: Friedreich's ataxia induced pluripotent stem cells model intergenerational GAATTC triplet repeat instability. Cell Stem Cell 2010, 7:631-637.

40. Swistowski A, Peng J, Han Y, Swistowska AM, Rao MS, Zeng X: Xeno-free defined conditions for culture of human embryonic stem cells, neural stem cells and dopaminergic neurons derived from them. PLoS One 2009, 4:e6233.

41. Hargus G, Cooper O, Deleidi M, Levy A, Lee K, Marlow E, Yow A, Soldner F, Hockemeyer D, Hallett PJ, Osborn T, Jaenisch R, Isacson O: Differentiated Parkinson patient-derived induced pluripotent stem cells grow in the adult rodent brain and reduce motor asymmetry in Parkinsonian rats. Proc Natl Acad Sci U S A 2010, 107:15921-15926.

42. Lucas-Meunier E, Fossier P, Baux G, Amar M: Cholinergic modulation of the cortical neuronal network. Pflugers Arch 2003, 446:17-29.

43. Bissonnette CJ, Lyass L, Bhattacharyya BJ, Belmadani A, Miller RJ, Kessler JA: The controlled generation of functional basal forebrain cholinergic neurons from human embryonic stem cells. Stem Cells 2011, 29:802-811.

44. Marchetto MC, Carromeu C, Acab A, Yu D, Yeo GW, Mu Y, Chen G, Gage FH, Muotri AR: A model for neural development and treatment of Rett syndrome using human induced pluripotent stem cells. Cell 2010, 143:527-539.

45. Hussein SM, Batada NN, Vuoristo S, Ching RW, Autio R, Narva E, Ng S, Sourour M, Hamalainen R, Olsson C, Lundin K, Mikkola M, Trokovic R, Peitz M, Brustle O, Bazett-Jones DP, Alitalo K, Lahesmaa R, Nagy A, Otonkoski T: Copy number variation and selection during reprogramming to pluripotency. Nature 2011, 471:58-62

46. Gore A, Li Z, Fung HL, Young JE, Agarwal S, Antosiewicz-Bourget J, Canto I, Giorgetti A, Israel MA, Kiskinis E, Lee JH, Loh YH, Manos PD, Montserrat N, Panopoulos AD, Ruiz S, Wilbert ML, Yu J, Kirkness EF, Izpisua Belmonte JC, Rossi DJ, Thomson JA, Eggan K, Daley GQ, Goldstein LS, Zhang K: Somatic coding mutations in human induced pluripotent stem cells. Nature 2011, 471:63-67.

47. Lister R, Pelizzola M, Kida YS, Hawkins RD, Nery JR, Hon G, AntosiewiczBourget J, O'Malley R, Castanon R, Klugman S, Downes M, Yu R, Stewart R, Ren B, Thomson JA, Evans RM, Ecker JR: Hotspots of aberrant epigenomic reprogramming in human induced pluripotent stem cells. Nature 2011, 471:68-73.

doi:10.1186/scrt73

Cite this article as: Peng J, Zeng X: The role of induced pluripotent stem cells in regenerative medicine: neurodegenerative diseases. Stem Cell Research \& Therapy 2011, 2:32. 